\title{
ON THE ANNEALING OF WHITE CAST IRON.
}

BY CHARLES JAMES,

Member of the Institute.

The paper on the annealing of white cast iron, which 1 have to present to you this evening, is not based upon laboratory experiments, but is an abstract of results obtained from daily business practice, extending over a con. siderable period of time. But, though these investigations were made for the guidance of commercial operations, they seemed to be of sufficient metallurgical interest to justify their presentation to you this evening.

The irons used in these operations were all of Bessemer quality, smelted with coke, no charcoal or other special iron being used. The melting furnace charges consisted of a mixture of gray and white irons, of which the following is an average analysis:

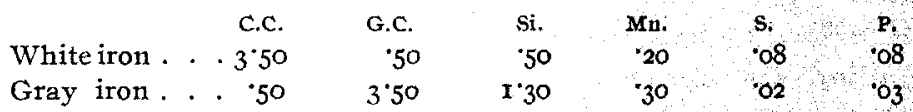

The charges varying from is per cent. to 25 per cent. white iron, from 50 per cent. to 60 per cent. gray iron, and from 20 to 30 per cent. scrap iron from previous meltings. The variations being made in accordance with the variations in the components of the pig iron and the deseription of casting required.

The composition of the charges was regulated by the silicon content, which was made to vary from $1: 20$ to :90 of I per cent.

The higher percentages of silicon being employed when very hot and very fluid metal was required.

The average chemical composition of these mixtures being :

Per cent.

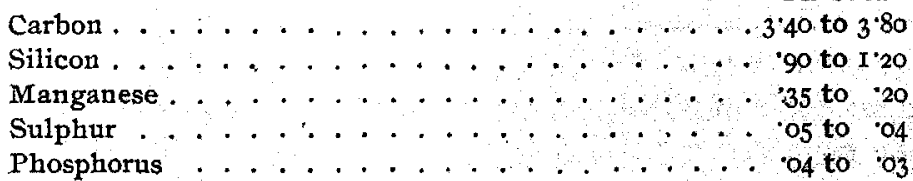


The iron was sometimes smelted in a cupola, but generally in an air furnace. The air-furnace charges were from 3 to 5 tons, and the furnace pre-heated to nearly a melting temperature before introducing the charge. The time occupied in melting was usually from three and onequarter to three and three-quarters hours. As soon as the charge had completely melted, the bath was well rabbled, to obtain as complete a mixture as possible. Test pieces 8 inches long and $1 \frac{1}{4}$ inches in diameter were then taken, and as soon as the iron had solidified the test pieces were rapidly cooled and broken. They usually showed a gray or highly mottled fracture, and the subsequent operations were conducted accordingly. The fining and final heating of the metal generally occupied from thirty to forty-five minutes, and was continued until a similar test piece was obtained free from all traces of gray iron. The casting made from such iron, however, frequently contains some graphite, due possibly to the different condition of cooling; but this graphite rarely exceeded one-half of I per cent., as the following analysis, which is an average from a large number of such castings, will show:

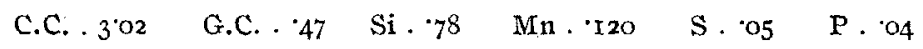

The annealing-furnace charges varied from 2 to 3 tons, the castings being placed either in the open furnace and the flame and furnace gases allowed to pass uninterruptedly over and between them, or packed in covered boxes of cast or wrought iron. No difference in the results, except as to scale, was to be observed or detected by either chemical analysis or physical tests, provided the heat treatment was conducted so as to compensate for the changed conditions. Castings packed in boxes, being practically solids of the same dimensions as the boxes, require a longer time to attain the same heat condition throughout their mass than do individual castings treated in the open fur. nace. But, as castings packed in boxes retain their heat for a greater length of time, and as the annealing effect continues for some time after the mass begins to cool, the total time required for either operation is nearly the same. 
The weight of the various castings treated ranged from half $\left(\frac{1}{2}\right)$ an ounce to 2,000 pounds and over. The time required to effect the carbon change-to be hereafter described-varied from three and one-half to ten hours, from the time the castings had attained their full temperature. The temperature at which the carbon change takes place in castings of this description lies between the melting points of silver and copper, and may, therefore, be approximately taken as $\mathrm{r}, 850^{\circ} \mathrm{F}$.

The change in the condition of the carbon, in irons of different composition, occurs at different temperatures. The range of temperature, however, at which the changes take place in different irons is not very great, and is always closely related to and governed by the temperature of their solidification, and this temperature in turn is largely governed by the relative amounts of carbon, silicon, manganese and sulphur contained in the iron.

For irons of similar composition, the length of time required to complete the annealing effect in any casting depends upon the section area of that casting.

Thus, of two castings of similar chemical composition before annealing, but of different sectional areas, the one weighing 53 and the other 1,890 pounds, the smaller casting, after three and one-half hours' annealing, had the following chemical composition :
c.c. . . . $6 \mathrm{r}$
G.C. . $2: 83$

and the larger casting, after seven and one-half hours' annealing, gave:

c.C. . . . 165

G.C. . . $\times 185$

This casting had to be returned to the furnace and subjected to a further annealing of three and one-half hours' duration, after which it approximated closely in chemical composition to the smaller casting.

The change of carbon in castings subjected to the annealing process, though gradual, is co-extensive throughout any given cross-section of the casting; no hard center or core of white iron, surrounded by softer metal, having ever been observed in any of the castings examined. No matter at 
what period the annealing process may have been arrested, the total surface of any fracture always showed a similarity in the condition of the metal, provided the composition of the metal was homogeneous, and the heat treatment had been applied equally to all parts of the casting.

We will now consider the nature of the change or changes that occur in the casting during annealing, and to enable us to do this we will take the analysis of an average casting produced by this process, both before and after annealing :

Before annealing . C.C., 2.60 G.C., $72 \mathrm{Si,} 7 \mathrm{I} \mathrm{Mn,} \mathrm{IIO} \mathrm{S,} 045$ P, 039

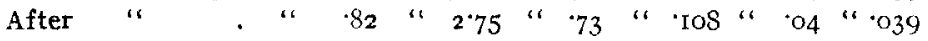

From these analyses it will at once be seen that the only change effected is one of condition in the carbon, a large proportion of which has passed from the combined into the graphite state. I wish, however, to say that, though for convenience the term graphite is employed in stating the analyses of these castings after annealing, the condition of the carbon-as I shall presently show-differs very materially from graphite, either as found free in nature or as solidified out from gray iron during cooling.

It has already been shown that the relative quantity of combined and graphitic carbon found in any specimen of iron after annealing depends upon the heat treatment it has received in relation to its chemical composition and sectional area. And it now remains to inquire what effect the other components of the iron exert upon the carbon change. This question has been directly investigated only so far as silicon, manganese and phosphorus are concerned. And of these phosphorus can at once be dismissed with the remark that, in all cases, it was found to be inoperative, at least in the small amount in which it was present in these castings.

With respect to sulphur, the investigations are not yet completed, but are still in progress, and, at a future date, I may be able to lay before the Section some data respecting its influence.

Both silicon and manganese exert great influence upon the carbon during the annealing process, the presence of 
silicon being a necessary condition to the carbon change. In low silicon irons it is very difficult, and, in some cases. impossible, to effect the carbon change no matter how 10 ng the iron is exposed to the heat treatment. This fact is, strikingly illustrated in the following example:

A casting about $\frac{5}{16}$ inch in thickness and weighing less than one pound, and of the following composition:
C.C. . . 2.08
G.C. . . none
Si . . . 42
Mn . . . o5

was subjected to the usual treatment, but after being annealed for three and one-half hours the casting was still hard, and had a white iron fracture, and analyzed
C.C. . . I 97
G.C. . . . none

After a second annealing of three and one-half hours the appearance of the casting was still unaltered; and the analyses gave:
C.C. . . I.98
G.C. . . trace

Subjected to a third annealing of three and one-half hours the casting was still hard and had a white iron fracture, and analyzed
C.C. . . I.90
G.C. . . I

Thus, after being exposed for ten and one-half hours to the full annealing temperature, as well as passing three times, through the much longer period of heating and cooling, only' I4 of I per cent. of the combined carbon had been changed to the graphite state.

In the example just given, both carbon and manganese, as well as the silicon, are comparatively of low percentage.

In the following instance, however, the carbon and manganese are both of fairly high percentage, but the casting, after repeated annealings, analyzed
c.C. . I 176
G.C. . . . r.08
Si . . . 3I
$\mathrm{Mn}$. . . I26

and the iron remained hard and white, and could not be machined.

Indeed, the relative amount of carbon that can be changed from the combined to the graphite state during annealing 
seems to be directly proportionate to the amount of silicon present, as indicated by the following example, in which all three samples were taken from the same cast, annealed in the same furnace at the same time and under identical conditions :

\begin{tabular}{|c|c|c|c|}
\hline $\mathrm{C}$. & G.C. . I 40 & $\cdot 56$ & $\mathrm{Mn}$. \\
\hline No, $2-\mathrm{C}$. & G.C. . I.33 & 45 & n. $\cdot 1_{30}$ \\
\hline No. 3-C.C. . . I 87 & G.C. . I. I 3 & $\mathrm{Si}$. & Mn . \\
\hline
\end{tabular}

In this instance the total carbon and the manganese are practically the same in all three examples, and of comparatively high percentage, the silicon being the only varient, except the condition of the carbon, which is less and less changed as the silicon in the iron decreases.

That low carbon, or at least comparatively low carbon, does not prevent the change in the carbon condition taking place seems well illustrated in the following example of a comparatively low carbon iron subjected to three and onehalf hours' annealing :

$\begin{array}{lllll}\text { Before anneating } & \text {. C.C. I'94 } & \text { G.C. . none } & \text { Si. } \cdot 64 & \mathrm{Mn} \cdot{ }^{\circ} 09 \\ \text { After " } & \text {.C.C. . none } & \text { G.C. . } 2 \cdot 00 & \text { Si. } 62 & \mathrm{Mn} \cdot \text { I Io }\end{array}$

In this instance the percentage of silicon is slightly under the normal amount usually present in this class of castings, while the manganese is well up to its average in such castings.

The influence of the manganese on the carbon change is not nearly so marked as that of silicon, and its action is further obscured by the high silicon which always accompanies high manganese, for, as the percentage of manganese rises in the casting, the percentage of silicon rises also. Comparatively high manganese, however, assists the carbon change and shortens the time necessary for its completion. This is illustrated in the following analyses of a high manganese casting after being annealed for three hours only :

$\begin{array}{lllll}\text { Before annealing. C.C. } \cdot 3 \cdot 68 & \text { G.C. none } & \text { Si. } 93 & \mathrm{Mn} \cdot 30 \\ \text { After } " & \text {.C.C. . none } & \text { G.C. } 3 \cdot 62 & \text { Si. } 95 & \text { Mn } \cdot 31\end{array}$

In this instance the casting showed signs of overannealing, and the process had evidently been carried on much longer than was necessary. 
The action of silicon and of manganese upon the carbon change is apparently of an essentially different character, that of silicon being direct upon the carbon, compelling it to change its condition, while the influence of the manganese is only indirectly upon the carbon through the silicon by protecting the latter from oxidation during the melting of the iron, thus causing the percentage of the silicon in the casting to be higher than it would be if the manganese had itself been more completely oxidized from the bath. This also accounts for the fact that comparatively high silicon and comparatively high manganese and the reverse are always coincident.

In every case, however, irons low in silicon and manganese are practically worthless after annealing. Such irons may be softened by the process, so as to machine easily, but are always deficient in tenacity. They generally have a white fracture, in appearance like that of a 30 per cent. carbon Bessemer steel bar. The analyses, after annealing, of two such irons are given for comparison:
No. I-C.C. . . $2 \cdot 65$
G.C. . . none
$\mathrm{Si} . .46$
Mn . . trace
No. 2 -C.C. . . r 97
G.C. . none
$\mathrm{Si} .{ }^{42}$
Mn , . none

The analysis shows that there was no change of the carbon conditions during annealing. The samples machined easily, but broke to pieces under the pressure of the lathe tool.

That this change of carbon, from the combined to the graphite condition, can be produced by this method of annealing in other combinations of iron and earbon, as well as in white iron castings, is proved by the following experiment carried out upon a hammered bar of crucible tool steel, which analyzed before annealing:
C.C. . . 97
G.C. . none
Si . . 32
Mn. . 3I

After four hours of annealing, the sample exhibited only the appearance of well-annealed tool steel, except that a skin of bright iron, similar to that seen around some malleable iron casting, had appeared. After a second annealing for four hours, the bright skin had deepened into the bar, and the remaining portion of the cross-section had a leady 
appearance. After a third annealing of four hours, the bright skin had increased still more in depth, and the remaining portion of the cross-section had become black with graphite carbon, some bright spots, however, still. being visible. The bar then analyzed:
C.C. . . 47
G.C. . . 42
Si . . 38
Mr1 . . 30

showing that nearly 50 per cent. of the carbon had changed its condition, the loss of carbon shown by this analysis being due to the decarbonizing of the surface of the bar.

Lastly we have to consider the nature of the carbon found in the castings after annealing. The carbon thus formed is evidently identical with what Ledebur has called "tempering graphite carbon," and is an allotropic form of graphite, and not merely amorphous carbon, since I find, by experiment, that it differs from both these varieties of carbon in its specific gravity, specific heat and calorific power, which after careful examination $I$ find to be as follows:

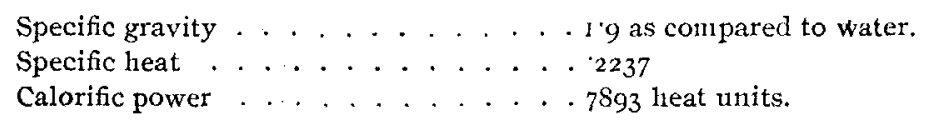

That this allotropic form of graphite should have been mistaken for a graphite similar to that of gray cast iron, though it has none of the bright scaly luster of the latter, is not surprising, since it can be both separated from the iron, and chemically determined in the same manner as the graphite, from gray iron, though its combustion is much more difficult.

The chemical and physical condition attending the formation of this allotropic graphite during the annealing process, and its probable molecular form, as well as the position it occupies in the structure of the casting, which differs so remarkably from the position occupied by graphite in gray iron, have already been described in a paper read by me before this Section in 1897. And I need not now refer to this part of the subject, further than to say that the change, as at that time pointed out, affords a striking example of the solution of one solid in another, at temperatures below the melting point of either. 
Contrary to Ledebur's statement, that "tempering graphite carbon" is unaffected by the hardening process, I find that iron containing this allotropic graphite hardens and tempers excellently well, and that when not fully developed by over-long annealing, the whole of this carbon will pass into the hardening state and leave the iron without a trace of free carbon.

I also find that, by prolonged heating, this allotropic form of graphite becomes changed to graphite identical with that found in gray iron, and that it then occupies a similar position in the iron structure, and greatly injures its physical qualities, so that overannealing should at all times be carefully avoided.

\section{Photographic and Microscopic Section.}

Stated Meeting, held Thursday, May 3 , rooo.

NOTES ON GOLD.SODIUM CHLORIDE.

BY LYMAN F. KEBLER.

If any one will take the trouble to obtain quotations from the various manufacturers, or consult their price lists, it will become apparent at once that there must be either a considerable margin of profit for some, or that the gold-sodium chloride varies much in composition. The difference in prices, or information on the labels are such, however, that the various makes come into direct competition with one another. For example, I ounce of gold-sodium chloride, U.S.P., in $\frac{1}{8}$-ounce vials, is quoted by several makers (wholesale price list) at $\$ 5.90, \$ 6.10, \$ 7.50, \$ 9.60$ and $\$ 14.50$, respectively. Again, some makes, without any specifications as to quality, are generally quoted a few cents below those containing information as to quality.

It must be remembered that the I 890 Pharmacopœia requires this article to contain 30 per cent. of metallic gold, and a commercial article may contain less for photographic 